\title{
A quasi-analytical model for the under-ice boundary layer
}

\author{
Miles G. MaPheE \\ McPhee Research Company, 450 Clover Springs Road, Naches, WA 98937, U.S.A.
}

\begin{abstract}
An implicit, analytical model for momentum, heat and salt flux within a sea-ice/upper-ocean system is developed. The model comprises three parts: (a) an equation for turbulent stress in the oceanic boundary layer and upper pycnocline, from which turbulent scalar fluxes are derived; (b) a model for heat and mass transfer in a thin sub-layer near the ice/ocean interface; and (c) a model for momentum flux lost to the internal wave-field if the ice under-surface has large-scale (pressure-ridge keel) relief. Features of the model are demonstrated by simulating response of the ice drift and upper-ocean temperature and salinity structure to constant heating and variable surface stress.
\end{abstract}

\section{INTRODUCTION}

An important aspect of sea-ice modeling (or upper-ocean modeling when sea ice is present) is properly describing the response of fluxes of momentum, heat and salt within the ice/upper-ocean system to changes in external forcing. This is a demanding task, even under ideal conditions, and is most often approached by formulating time-dependent, multi-level numerical models with some form of turbulence closure (e.g. Mellor and others, 1986; McPhee, 1987; Mellor and Kantha, 1989; Svennson and Omstedt, 1990). There are times, however, when one wishes to avoid the extensive computational effort required of the numerical models, yet retain a more credible description of turbulent fluxes than can be obtained with simple exchange coefficients. This paper presents a "quasi-analytical" model that fills this niche, based primarily on steady-state, Ekman dynamics and scaling arguments that consider the effect of rotation, buoyancy and proximity to the interface on turbulent exchange.

\section{SYMBOLS}

$a=\sqrt{2 k \xi_{N}} \quad$ scalar attenuation coefficient in the turbulence model

proportionality constant in the heat and mass transfer model; also indicates buoyancy in the context of Equation (4)

$c_{\mathrm{wd}} \quad$ internal wave-drag coefficient

$K \quad$ eddy viscosity

$K_{\mathrm{p}}$

$K_{*}$

$K_{* \mathrm{p}}$

$k$

$k_{\mathrm{c}}=N / u_{0}$

eddy viscosity at mixed-layer/

pycnocline interface

non-dimensional eddy viscosity

non-dimensional eddy viscosity at

mixed-layer/pycnocline interface

von Karman's constant

critical wavenumber in the
$L=\frac{u_{+}^{3}}{k\left\langle w^{\prime} b^{\prime}\right\rangle}$

internal wave model
$L_{\mathrm{p}}$

$l$

$\operatorname{Pr}=\nu / \kappa$

$Q_{\mathrm{L}}$

$R e=\frac{u, 0 h h_{\mathrm{sl}}}{\nu}$

$R_{\mathrm{b}}$

$S$

$T$

$\widehat{u}_{0}$

$\widehat{u}_{*}=\widehat{\tau} / \tau^{1 / 2}$

$u_{* 0}$

$u_{* \mathrm{p}}$

$w$

$w_{0}$

$\left\langle w^{\prime} b^{\prime}\right\rangle$

$\left\langle w^{\prime} S^{\prime}\right\rangle$

$\left\langle w^{\prime} T^{\prime}\right\rangle$

$\alpha$

Obukhov length

Obukhov length at mixed-layer/

pycnocline interface

vertical eddy exchange scale

Prandtl number

latent heat of saline ice divided by

specific heat of sea water

Reynolds number for the transition sub-layer

buoyancy jump Richardson number in the internal wave model salinity temperature

ice velocity with respect to the undisturbed ocean

turbulent friction velocity, complex vector

interface friction velocity,

complex vector

friction velocity at mixed-layer/ pycnocline interface

vertical velocity of the ice/ocean interface

interface velocity due to melting or freezing at the interface vertical component of turbulent buoyancy flux

turbulent salinity flux

kinematic turbulent heat flux

ratio of eddy diffusivity to

eddy viscosity

$\Gamma \quad$ depth-attenuation coefficient

in the internal wave model

$\widehat{\gamma} \quad$ complex attenuation coefficient, pycnocline

$\widehat{\delta} \quad$ complex attenuation coefficient, mixed layer 


\begin{tabular}{|c|c|}
\hline$\eta_{*}$ & $\begin{array}{l}\text { stability parameter, } 1 \text { for neutral } \\
\text { stability }\end{array}$ \\
\hline$\zeta$ & non-dimensional vertical coordinate \\
\hline$\zeta_{\mathrm{p}}$ & non-dimensional mixed-layer depth \\
\hline$\widehat{T}$ & $\begin{array}{l}\text { non-dimensional turbulent stress, } \\
\text { complex vector }\end{array}$ \\
\hline$\widehat{T}_{\mathrm{p}}$ & $\begin{array}{l}\text { non-dimensional turbulent stress } \\
\text { at mixed-layer/pycnocline interface }\end{array}$ \\
\hline$\widehat{\tau}$ & $\begin{array}{l}\text { kinematic turbulent stress, } \\
\text { complex vector }\end{array}$ \\
\hline$\widehat{\tau}_{\text {iw }}$ & kinematic internal wave stress \\
\hline$\widehat{\widetilde{\tau}}$ & $\begin{array}{l}\text { kinematic stress at the ice-ocean } \\
\text { interface }\end{array}$ \\
\hline$v=k_{0} / k_{\mathrm{c}}$ & non-dimensional wavenumber \\
\hline 雨 & $\begin{array}{l}\text { non-dimensional scalar change in the } \\
\text { heat/mass sub-model }\end{array}$ \\
\hline$r$ & $\begin{array}{l}\text { total diffusivity in heat/mass } \\
\text { sub-model }\end{array}$ \\
\hline
\end{tabular}

\section{BASICS}

The quasi-analytical model comprises sub-models, including: (1) a model for turbulent flux of momentum and scalar properties in the mixed layer and upper pycnocline, collectively termed the oceanic boundary layer $(\mathrm{OBL}) ;(2)$ a heat and mass transport model for freezing or melting at the ice/ocean interface; and (3) an internal wave-drag model for transport of momentum and energy away from the ice-ocean boundary layer system in the internal wave field.

\section{The OBL turbulence model}

A similarity model for turbulent stress and velocity under varying conditions of buoyancy flux may be constructed by careful choice of scales describing the effect of interfacial stress, rotation and buoyancy on the largest, "energy containing" turbulent eddies in the flow (McPhee, 1981). A straightforward extension of the similarity concepts extends to the turbulent scalar flux in the mixed layer (McPhee, 1983), and at the interface between the mixed layer and pycnocline (McPhee, 1987). Details of the scaling arguments and derivation of the model are given in those references and McPhee (1990). Conceptually, the model expresses turbulent stress at any level in the mixed layer/upper pycnocline as a function of stress and buoyancy flux at the ice/ocean interface, depth of the mixed layer, the strength of the buoyancy jump at the base of the mixed layer and the buoyancy frequency, $N$, in the upper part of the pycnocline. The principal equation is

$$
i \frac{\widehat{T}}{K_{*}}=\frac{\partial^{2} \widehat{T}}{\partial \zeta^{2}},
$$

where $\widehat{T}$ is non-dimensional stress, defined by $\widehat{T} \equiv$ $\widehat{\tau} /\left(u_{* 0} \widehat{u}_{* 0}\right)$, with $\widehat{\tau}$ being the kinematic, turbulent stress, equal to $\widehat{\tau}_{0}$ at the interface, and vector friction velocity, $\widehat{u}_{* 0}$, is defined by $\widehat{\tau}_{0} \equiv u_{* 0} \widehat{u}_{* 0}$. The non-dimensional eddy viscosity is $K_{*}=f K /\left(u_{* 0} \eta_{*}\right)^{2}$, and the dimensionless vertical coordinate is $\zeta=(f z) /\left(u_{* 0} \eta_{*}\right)$. A righthanded coordinate system with $z$ positive upward is used.

In the mixed layer, the solution for stress is

$$
\widehat{T}=2 \widehat{A} \sinh (\widehat{\delta} \zeta)+e^{-\widehat{\delta \zeta} ;} \quad\left(0>\zeta \geq \zeta_{\mathrm{p}}\right),
$$

where $\widehat{\delta}=\sqrt{i / K_{* \mathrm{~m}}}$, and $K_{* \mathrm{~m}}=k \xi_{\mathrm{N}}$ is the nondimensional eddy viscosity in the mixed layer. In the lower layer,

$$
\widehat{T}=\widehat{T}_{\mathrm{p}} \widehat{e}^{\widehat{\gamma}\left(\zeta-\zeta_{\mathrm{p}}\right)} ; \quad\left(\zeta<\zeta_{\mathrm{p}}\right),
$$

where $\widehat{\gamma}=\sqrt{i / K_{* \mathrm{p}}}$, and $K_{* \mathrm{p}}$ is the eddy viscosity at the base of the mixed layer, incorporating both a discontinuous buoyancy jump, $\Delta b$, at the interface, and the density gradient in the upper part of the pycnocline. $\widehat{T}_{\mathrm{p}}$ is non-dimensional stress at the interface. It follows that

$$
\widehat{A}=\frac{(\widehat{\gamma}+\widehat{\delta}) e^{-\widehat{\delta} \zeta_{\mathrm{p}}}}{2\left[\cosh \left(\widehat{\delta} \zeta_{\mathrm{p}}\right)-\widehat{\gamma} \sinh \left(\widehat{\delta} \zeta_{\mathrm{p}}\right)\right]} .
$$

At the base of the mixed layer, turbulence is assumed to scale with the local Obukhov length, so that $K_{\mathrm{p}}=k u_{* \mathrm{p}} R_{\mathrm{c}} L_{\mathrm{p}}$, where $L_{\mathrm{p}}=u_{* \mathrm{p}}^{3} /\left(k\left\langle b^{\prime} w^{\prime}\right\rangle_{\mathrm{p}}\right)$ and $u_{* \mathrm{p}} \widehat{u}_{* \mathrm{p}}=$ $\widehat{T}_{\mathrm{p}} u_{* 0} \widehat{u}_{* 0}$. If $l=L_{\mathrm{p}} / R_{\mathrm{c}}$ is the vertical exchange scale at the interface, the buoyancy flux there is

$$
\left\langle w^{\prime} b^{\prime}\right\rangle_{\mathrm{p}}=\alpha u_{* \mathrm{p}}\left(\Delta b-k l \frac{\partial b}{\partial z}\right)=\alpha u_{* \mathrm{p}}\left(\Delta b+N^{2} k l\right),
$$

where $\alpha$ is the ratio of eddy diffusivity to eddy viscosity. Here, $\alpha$ is unity in the mixed layer, but is much smaller in the stable stratification of the upper pycnocline (minimum value, 0.1 ). An expression for its variation with Richardson number is described by McPhee (1987). Hence,

$$
l=\left\{-\frac{\Delta b}{k}+\sqrt{\left(\frac{\Delta b}{k}\right)^{2}+4 \frac{N^{2} u_{* \mathrm{p}}^{2}}{k^{2}} \frac{R_{c}}{\alpha}}\right\} \cdot\left(2 N^{2}\right)^{-1} .
$$

These equations can be combined to provide an implicit equation for $T_{p}$, the scalar magnitude on nondimensional turbulent stress at the pycnocline level, $z_{\mathrm{p}}$.

Mean velocity is obtained by direct integration of the complex stress equation, except in the "surface layer", where the exchange scale is governed by the distance from the ice/ocean interface. The surface layer extends in non-dimensional coordinates to $\zeta_{\mathrm{sl}}=-\eta_{*} \xi_{\mathrm{N}}$. For depths greater than $\left|\zeta_{\mathrm{p}}\right|$, non-dimensional velocity is given by

$$
\widehat{U}(\zeta)=-i \widehat{\gamma} \widehat{T}_{\mathrm{p}} e^{\widehat{\gamma}\left(\zeta-\zeta_{\mathrm{p}}\right)} .
$$

For $\zeta_{\mathrm{p}}<\zeta \leq \zeta_{\mathrm{sl}}$ (i.e. the mixed layer),

$$
\widehat{U}(\zeta)=\widehat{U}\left(\zeta_{\mathrm{p}}\right)-i \widehat{\delta}\left[2 \widehat{A} \cosh (\widehat{\delta} \zeta)-e^{\widehat{\delta} \zeta}\right] .
$$

In the surface layer, non-dimensional stress is approximated by a Taylor series expansion, $\widehat{T}=1+\widehat{\delta} \zeta$, and eddy viscosity is $K_{*}=-k \zeta / \eta_{*}$, thus velocity is

$$
\widehat{U}(\zeta)=\widehat{U}\left(\zeta_{\mathrm{sl}}\right)+\frac{\eta_{*}}{k}\left[\ln \frac{\zeta_{\mathrm{sl}}}{\zeta}+\widehat{\delta}\left(\zeta_{\mathrm{sl}}-\zeta\right)\right]
$$

Scalar fluxes are treated similarly (McPhee, 1983), e.g.

$$
\left\langle w^{\prime} T^{\prime}\right\rangle=-\alpha_{\mathrm{T}} K \frac{\partial T}{\partial z}
$$


where $\alpha_{\mathrm{T}}$ is the ratio of eddy diffusivity for heat to eddy viscosity.

\section{Heat and mass sub-model}

Oceanic heat flux plays an important role in the mass balance of sea ice. In marginal ice zones (MIZ), multiyear pack ice can often melt completely within a few days of drifting over relatively warm water. In the MIZ, melting ice stratifies as well as cools the upper ocean, which can significantly change the dynamics as well as the thermodynamics. Over extensive areas of the Weddell Sea, the growth of seasonal sea ice is rapidly curtailed at a thickness of around $50-60 \mathrm{~cm}$ as a balance is struck between conduction through the ice and upward oceanic heat flux (Gordon and Huber, 1990). This regime contrasts with the typical MIZ melting in that the large heat flux is not accompanied by buoyancy flux, because ice thickness remains relatively stationary.

Results from direct measurement of turbulent oceanic heat flux in the marginal ice zone (McPhee and others, 1987) and in other regions of the eastern Arctic have shown the importance of molecular effects in thin layers near the ice/ocean interface on the thermodynamics of heat and salt exchange. In this section, a submodel which describes the heat and salinity flux at the ice/ocean interface in terms of mixed-layer temperature and salinity, and interfacial friction velocity, $u_{* 0}$, is described, following the development of McPhee and others (1987).

The total melt rate of ice is expressed in terms of a vertical velocity of the ice/ocean interface which adjusts isostatically; i.e. $w=-\left(\rho_{\mathrm{i}} / \rho\right) \dot{d}=w_{0}+w_{\mathrm{i}}$, where $\dot{d}$ is the ice-growth rate, $\rho_{\mathrm{i}}$ is ice density, $w_{\mathrm{i}}$ is the "percolation velocity" due to melting at the surface or within the ice column and $w_{0}$ is the velocity due to melting or freezing at the ice/ocean interface. If thermal inertia in a thin layer near the ice is ignored, flux at the interface is equivalent to the turbulent heat flux at the top of the turbulent boundary layer, given by

$$
\left\langle w^{\prime} T^{\prime}\right\rangle_{0}=w_{0} Q_{\mathrm{L}}+\dot{q},
$$

where

$$
\dot{q}=-\left.\frac{k_{\mathrm{c}}}{\rho c_{\mathrm{p}}} \frac{\partial T}{\partial z}\right|_{\text {ice }}
$$

is heat conduction through the ice divided by specific heat $\left(\rho c_{\mathrm{p}}\right)$ and $Q_{\mathrm{L}}$ is latent heat of fusion, adjusted for brine volume associated with ice salinity, $S_{\mathrm{i}}$, divided by specific heat, with units of temperature: $Q_{\mathrm{L}}=Q_{0}(1-$ $\left.0.03 S_{\mathrm{i}}\right)$.

Expressing the flux as an exchange coefficient times the mean gradient, the non-dimensional change in temperature at level $z$ relative to the interface $\left(T_{0}\right)$ is given by

$$
\frac{u_{* 0}\left[T(z)-T_{0}\right]}{w_{0} Q_{\mathrm{L}}+\dot{q}}=\Phi_{\mathrm{T}}=\int_{z}^{0} \frac{u_{* 0}}{\mathcal{K}_{\mathrm{h}}} \mathrm{d} z^{\prime},
$$

where $\mathcal{K}_{\mathrm{h}}$ is total heat diffusivity, including both turbulent and molecular contributions.

Similarly, salinity flux at the interface is proportional to the total vertical interface velocity

$$
\left\langle w^{\prime} S^{\prime}\right\rangle_{0}=\left(w_{\mathrm{i}}+w_{0}\right)\left(S_{0}-S_{\mathrm{i}}\right),
$$

where $S_{0}$ is salinity of water at the interface. The corresponding non-dimensional salinity change is

$$
\frac{u_{* 0}\left[S(z)-S_{0}\right]}{\left(w_{0}+w_{\mathrm{i}}\right)\left(S_{0}-S_{\mathrm{i}}\right)}=\Phi_{\mathrm{S}}=\int_{z}^{0} \frac{u_{* 0}}{\mathcal{K}_{\mathrm{S}}} \mathrm{d} z^{\prime} .
$$

$T_{0}$ is the freezing temperature of water at the interface, approximately proportional to salinity, $T_{0}=-m S_{0}$. Given ice salinity, percolation velocity, heat conduction through the ice, and the non-dimensional functions $\Phi_{\mathrm{T}}$ and $\Phi_{\mathrm{S}}$, Equations (10) and (12) can be combined to yield a quadratic formula for $S_{0}$

$$
m S_{0}^{2}+\left[T_{\mathrm{q}}+\left(1+c_{1}\right) c_{2}-m S_{\mathrm{i}}\right] S_{0}-\left(T_{\mathrm{q}} S_{\mathrm{i}}+c_{2} S_{\mathrm{q}}\right)=0,
$$

where

$$
\begin{array}{cc}
c_{1}=\left(\Phi_{\mathrm{S}} w_{\mathrm{i}}\right) / u_{* 0}, & c_{2}=\left(\Phi_{\mathrm{T}} Q_{\mathrm{L}}\right) / \Phi_{\mathrm{S}}, \\
T_{\mathrm{q}}=T(z)-\left(\Phi_{\mathrm{T}} / u_{* 0}\right) \dot{q}, & S_{\mathrm{q}}=S(z)+c_{1} S_{\mathrm{i}},
\end{array}
$$

from which the bottom ablation velocity is

$$
w_{0}=\frac{S(z)-S_{0}}{\Phi_{\mathrm{S}}\left(S_{0}-S_{\mathrm{i}}\right)} u_{* 0}-w_{\mathrm{i}} .
$$

The important physics is specified by the nondimensional changes in temperature and salinity across the boundary layer. In order to explain observed heat flux and melt rates in the summer marginal ice zone, McPhee and others (1987) adapted a model suggested by Yaglom and Kader (1974) for laboratory observations of heat and mass transfers over hydraulically rough surfaces. Their method considers a "transition sub-layer" across which the flow changes from laminar to fully turbulent in approximately the same thickness as the roughness elements. Most of the change in temperature and salinity occurs within the inner part of the sub-layer, which contrasts sharply with the otherwise analogous behavior of momentum. In the turbulent part of the boundary layer, eddy viscosity and diffusivities are comparable, so that the total non-dimensional change in a scalar quantity may be written as $\Phi_{\text {total }}=\Phi_{\text {sublayer }}+\Phi_{\text {turb }}$. An approximation to the Yaglom-Kader result for large Prandtl (or Schmidt) numbers is

$$
\Phi_{\text {sublayer }}=b \sqrt{R e}(P r)^{2 / 3},
$$

where $R e=u_{* 0} h(\nu)^{-1}$ is a Reynolds number based on the friction speed and the thickness of the sublayer, $P r_{\mathrm{T}, \mathrm{S}}=$ $\nu / \kappa_{\mathrm{T}, \mathrm{S}}$ are the ratios of molecular viscosity and diffusivity for heat and salt, respectively, with $b$ approximately 0.6.

For sea ice, the sub-layer thickness, $h$, is not well known. For the laboratory studies, it was taken to be the uniform roughness-element size, which is about 30 times the surface roughness length, $z_{0}$. Using this ratio and the MIZEX result for surface roughness, the heat flux calculated using (16) was found to be about half the observed heat flux (McPhee and others, 1987). Therefore the constant in (16) was adjusted downward by that factor. However, we noted that, for typical sea ice, $z_{0}$ includes contributions from a large range of scales, and is not necessarily appropriate for scaling the transition sub- 
layer. Recent unpublished results from under-ice turbulence measurements indicate that $h$ is less variable than $z_{0}$, ranging from about 0.15 to $0.45 \mathrm{~m}$.

In the turbulent part of the boundary layer, beyond the transition sub-layer, we assume that scalar flux decreases in the same way as the magnitude of turbulent stress, i.e. exponentially. Thus,

$$
\frac{\partial \Phi}{\partial \zeta}=\frac{e^{a \zeta}}{K_{*}}
$$

where $a=\left(2 k \xi_{\mathrm{N}}\right)^{\frac{1}{2}}$. Typically, the transition sub-layer is embedded within the turbulent surface layer, and integration of (17) yields

$$
\Phi_{\mathrm{turb}}=\frac{1}{a k \xi_{\mathrm{N}}} e^{a \zeta_{\mathrm{sl}}}+\frac{\eta_{*}}{k}\left[\ln \frac{\eta_{*}^{2} u_{* 0} \xi_{\mathrm{N}}}{f h}-a \xi_{\mathrm{N}} \eta_{*}+\frac{a f h}{u_{* 0} \eta_{*}}\right]
$$

In general, $\Phi_{\text {turb }}$ is much smaller than $\Phi_{\text {sublayer }}$, meaning that the change in a scalar property across the turbulent boundary layer is small compared with its change across the transition sub-layer, amounting to a few per cent for temperature and less than $1 \%$ for salinity.

\section{The internal wave-drag sub-model}

Melting sea ice often creates strong buoyancy near the surface and, as pressure-ridge keels are dragged through the stratified fluid, they generate internal waves capable of significant momentum and energy flux away from the boundary layer. McPhee and Kantha (1989) formulated a simple parameterization of this process that successfully explained otherwise peculiar ice-drift behavior near the end of the MIZEX-84 drift in the Greenland Sea MIZ (Morison and others, 1987). For the present work, those results can be summarized as follows.

We characterize the spectrum of under-ice relief (or "waviness") by a peak horizontal wavenumber, $k_{0}$, and an equivalent amplitude, $h_{0}$. As with the turbulence model, the upper ocean comprises a mixed layer of depth $H$ separated from a lower layer with buoyancy frequency $N$ by a discontinuous buoyancy jump, $\Delta b$.

We define a drag coefficient, $c_{\mathrm{w}}$, by the relationship $\widehat{\tau}_{\text {iw }} \equiv-c_{\mathrm{w}} u_{0} \widehat{u}_{0}$, where $\widehat{\tau}_{\text {iw }}$ is the kinematic drag due to internal waves and $\widehat{u}_{0}$ is ice velocity with respect to the undisturbed ocean just beyond the OBL. The drag coefficient is the product of two factors: $c_{\mathrm{w}}=\Gamma c_{\mathrm{wd}}$, where $c_{\mathrm{wd}}$ is the drag that would exist if stratification extended to the ice/ocean interface and $\Gamma$ is an attenuation factor incorporating the effect of mixed-layer depth and the buoyancy jump at the base of the mixed layer. A critical wavenumber, $k_{\mathrm{c}}=N / u_{0}$, exists for which higher wavenumber disturbances are evanescent and the ice "outruns its internal wake". In other words, as ice speed increases, the drag decreases. If a spectrum of under-ice roughness is considered, there is no abrupt cutoff wavenumber (McPhee and Kantha, 1989). The results of the model are

$$
\frac{c_{\mathrm{wd}}}{\left(k_{\mathrm{c}} h_{0}\right)^{2}}=\frac{v}{2}\left(1-v^{2}\right)^{1 / 2}, \quad 0<v<1,
$$

where $v=k_{0} / k_{\mathrm{c}}$, and the attenuation factor is
$\Gamma=\left\{1+\left(\frac{1}{v^{2}}+R_{\mathrm{b}}^{2}\right) \sinh ^{2}\left(k_{0} H\right)-R_{\mathrm{b}} \sinh \left(2 k_{0} H\right)\right\}^{-1}$,

where $R_{\mathrm{b}}=\Delta b /\left(k_{0} u_{0}^{2}\right)$.

Internal wave drag enters the model system as a component of the kinematic water-stress at the ice-ocean interface, i.e.

$$
\widehat{\tau}_{\mathbf{w}}=-\left(u_{* 0} \widehat{u}_{* 0}+\Gamma c_{\mathrm{wd}} u_{0} \widehat{u}_{0}\right) .
$$

\section{USING THE MODEL}

\section{Input}

Parameters that drive the model are as follows:

Ice parameters

$z_{0} \quad$ small-scale roughness of the under-side

$h_{\mathrm{sl}} \quad$ thickness of the transition sub-layer

$h_{0}, k_{0}$ amplitude, wavenumber describing the large-scale under-ice relief

$\dot{q}, w_{\mathrm{i}} \quad$ heat conduction in the ice, interface velocity

$S_{\mathrm{i}} \quad$ ice salinity

Ocean parameters

$\widehat{\tau}_{w} \quad$ total kinematic stress at the ice/ocean interface

$H, T_{\mathrm{ml}}, S_{\mathrm{ml}} \quad$ depth, temperature, salinity of the mixed layer

$\Delta b, N \quad$ buoyancy jump at the base of the mixed layer, buoyancy frequency in the pycnocline

$f \quad$ Coriolis parameter

Constants

$\xi_{\mathrm{N}} \quad$ dimensionless maximum eddy size,

equal to 0.05

$R_{c} \quad$ critical flux Richardson number, equal to 0.2

$m \quad$ freezing-line slope, equal to 0.0549

$\nu, \kappa_{\mathrm{T}}, \kappa_{\mathrm{S}} \quad$ molecular kinematic viscosity, thermal diffusivity, salt diffusivity. Values $\left(\mathrm{m}^{2} \mathrm{~s}^{-1}\right)$ are $1.8 \times 10^{-6}$, $1.3 \times 10^{-7}$ and $7.4 \times 10^{-10}$, respectively

$Q_{0} \quad$ "kinematic" latent heat of fresh ice, equal to $83.8 \mathrm{~K}$

\section{Example}

Performance of the model is demonstrated by considering the response of ice drift, temperature and salinity in the upper ocean to an idealized forcing in which a constant (warming) heat flux of about $180 \mathrm{~W} \mathrm{~m}^{-2}$ is introduced at the interface (via $\dot{q}$ ), and the total stress at the ice/ocean interface is varied smoothly from moderately strong $(0.15 \mathrm{~Pa})$ to weak and then back to its original value over a $10 \mathrm{~d}$ period (Fig. 1a). The mixed layer is initially at freezing, $36 \mathrm{~m}$ deep. Temperature and salinity fields are discretized with $4 \mathrm{~m}$ spacing in the upper $44 \mathrm{~m}$, and up-dated every $6 \mathrm{~h}$, using surface and pycnocline fluxes as determined by the model.

In the solution algorithm, if the current mixed-layer depth exceeds the dynamic boundary-layer depth by a meter or more, a new mixed layer is formed, and information about the "remanent" mixed layer is pushed onto 

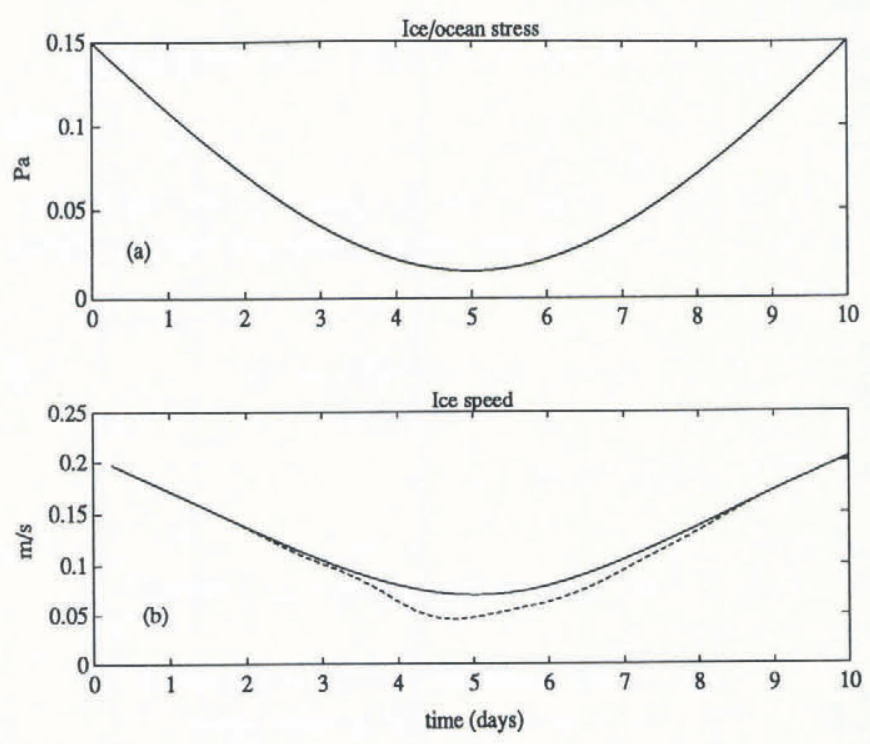

Fig. 1. (a) Specified total stress (including turbulent and internal-wave stress) at the ice/ocean interface; (b) corresponding ice-drift speed for case 1 , without internal wave drag (solid for all figures) and case 2, with internal wave drag (dashed for all figures). Scalar fields shown in Figures 1 through 4 have been smoothed with a four-point (1 d) running average.

an expanding stack. In this way, the retreat of the mixed layer as ice melts can be followed closely despite a fairly coarse vertical grid. Entrainment reverses the process, working successively through the remanent mixed layers until the last is removed from the stack.

Two different model runs were made: one in which the ice under-surface was given a small-scale roughness length of $2 \mathrm{~cm}$, but is otherwise smooth; and a second, with the same value for $z_{0}$, but with large-scale relief with
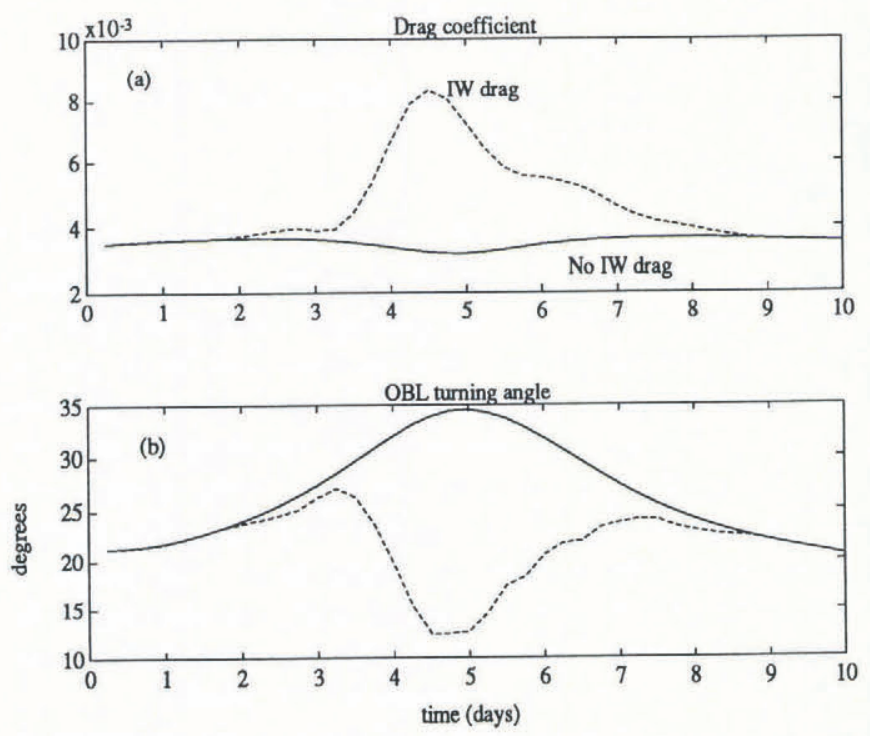

Fig. 2. (a) Effective drag coefficient. (b) Magnitude of the angle between interfacial stress and surface (ice) velocity.
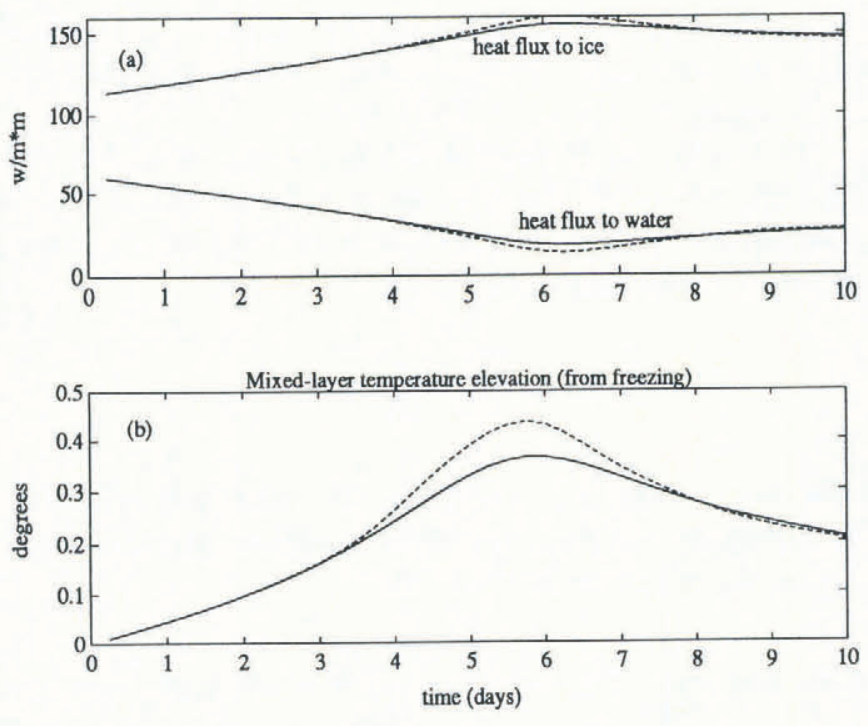

Fig. 3. (a) Heat flux to the ice (i.e. bottom melting) and to the mixed layer. (b) Difference between mixed-layer temperature and mixed-layer freezing temperature. The model is initially at freezing.

$k_{0}=0.063 \mathrm{~m}^{-1}$ and $h_{0}=1.4 \mathrm{~m}$ (McPhee and Kantha, 1989) in order to assess the impact of the internal wave model.

Figures 1 and 2 show the response of ice drift. Early on, the mixed layer is deep and the drag coefficients are similar. As the wind dies, meltwater begins to accumulate nearer the surface and the resulting stratification affects the drift response in dramatically different ways: for the case with no internal wave drag, there is a slight decrease in the magnitude of the drag coefficient and a substantial increase in the turning angle, i.e. the angle between interfacial stress and surface-drift velocity. With large-scale underside relief, momentum is transferred directly into the internal wave-field, so that drag increases by a large factor and the turning angle decreases. As the wind picks up in the second half of the period, the mixed layer deepens (Fig. 4a), lessening
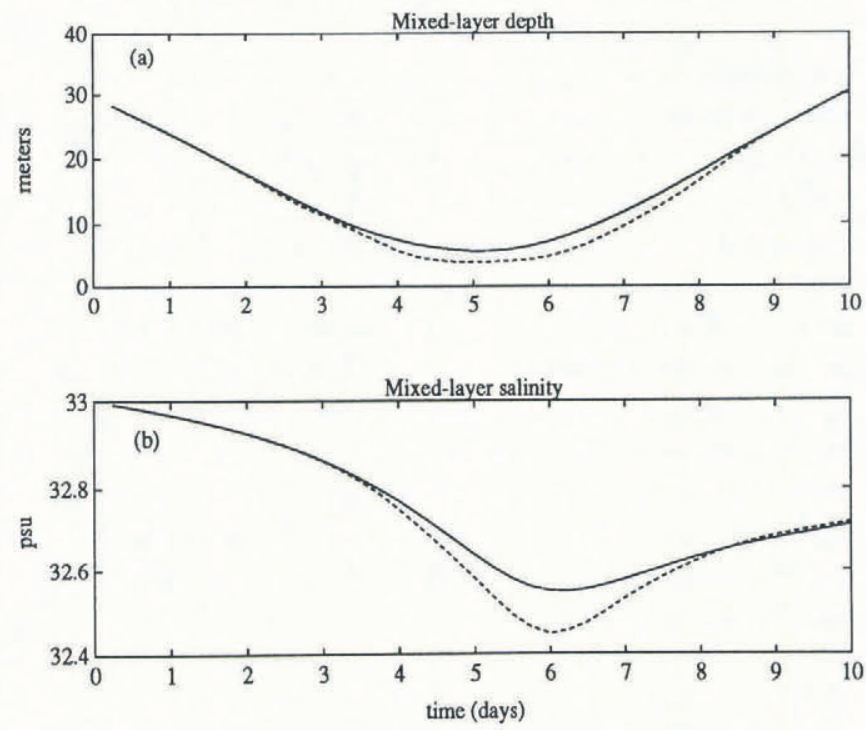

Fig. 4. (a) Mixed-layer depth. (b) Mixed-layer salinity. 


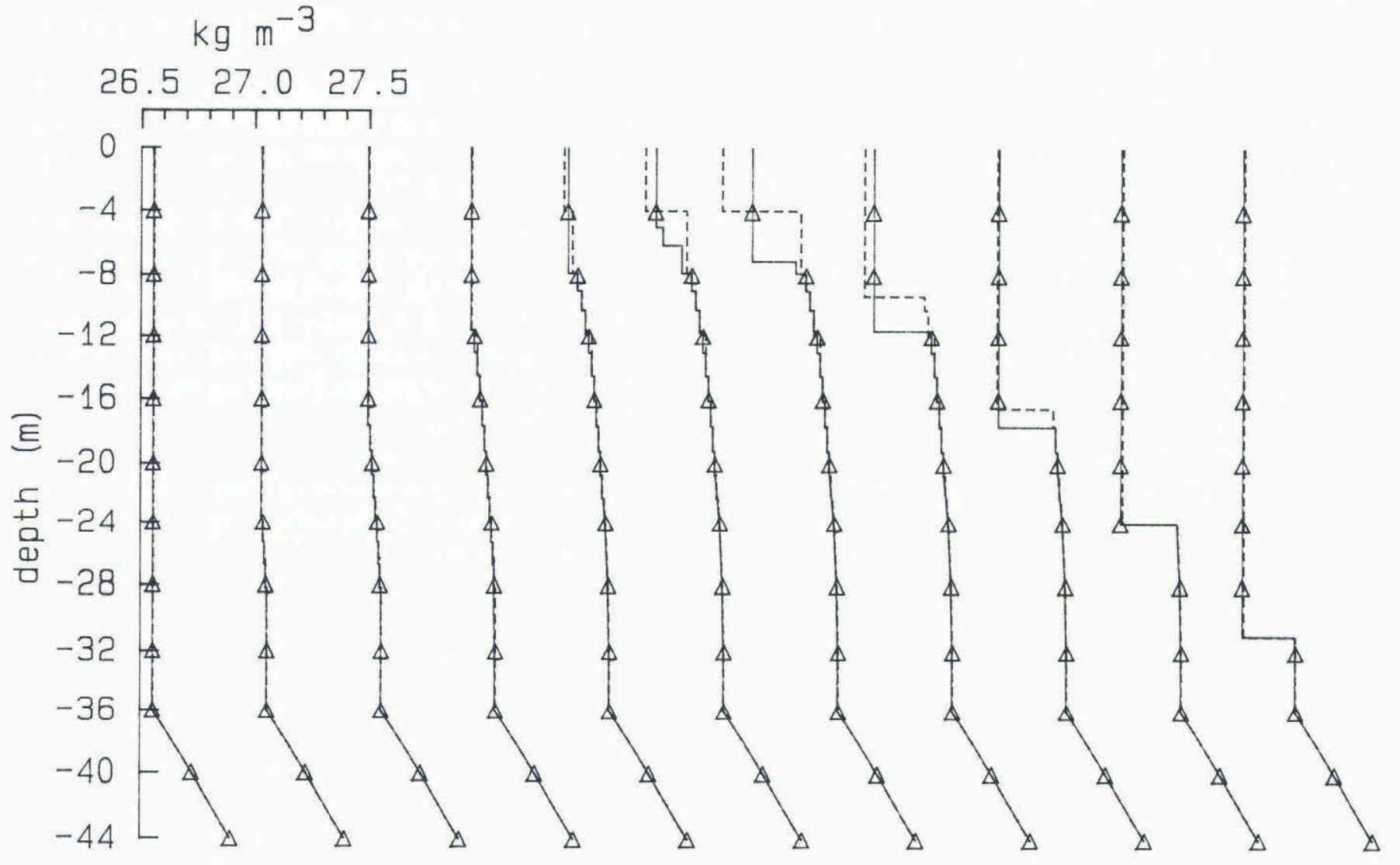
$m^{-3}$

Fig. 5. Density (-1000) profiles for successive days. Triangles show grid-point values for case 1 , while the solid and dashed curves show step structure retained by the "remanent mixed-layer" stack. Note that density remains unchanged at the bottom four grid points.

momentum loss to internal waves, and eventually the ice gains enough speed to outrun its internal wake.

Thermodynamics is summarized in Figure 3. Most of the heat flux introduced at the interface melts ice ( $150 \mathrm{~W} \mathrm{~m}^{-2}$ is roughly equivalent to $5 \mathrm{~cm} \mathrm{~d}^{-1}$ ice melt), but note that, in the first few days, a substantial proportion goes to heating the mixed layer (Fig. 3b).

Mixed-layer salinity (Fig. 4b) decreases overall in response to the influx of fresh meltwater at the surface, but increases from a minimum on day 6 as turbulent entrainment is forced by the increasing surface stress. A more detailed view of the density structure is provided by Figure 5 , showing daily density $(-1000)$ profiles in succession. The symbols denote values at grid points, but the intermediate step-structure associated with the remanent mixed layers is also shown. By the end of the period, all of the remanent mixed layers have been entrained.

\section{SUMMARY}

A quasi-analytical upper-ocean model has been developed for describing fluxes of momentum, heat and salt at the ice/ocean interface, and within the mixedlayer/upper pycnocline system. The model incorporates ideas suggested by recent observational studies, including a realistic model for heat and mass transfer at the ice/ocean boundary, and a treatment of momentum flux lost from the ice/upper-ocean system in the internal wave-field.
The turbulence model provides a detailed account of velocity and Reynolds stress structure in the turbulent boundary layer and, as such, is considerably more complex than most "slab" type mixed-layer models (e.g. Houssais, 1988). Nevertheless, it can be used in a model of upper-ocean temperature and salinity with relatively coarse vertical and time resolution.

\section{ACKNOWLEDGEMENTS}

Support for this work by the Office of Naval Research, through Contract N00014-84-C-0028, and by the National Science Foundation, through Grant OCE-8923072, is gratefully acknowledged.

\section{REFERENCES}

Gordon, A.L. and B. Huber. 1990. Southern Ocean winter mixed layer. J. Geophys. Res., 95(C11), 11,65511,672 .

Houssais, M.-N. 1988. Testing a coupled ice-mixedlayer model under subarctic conditions. J. Phys. Oceanogr., 18(2), 196-210.

McPhee, M.G. 1981. An analytic similarity theory for the planetary boundary layer stabilized by surface buoyancy. Boundary-Layer Meteorol., 21, 335-340.

McPhee, M.G. 1983. Turbulent heat and momentum transfer in the oceanic boundary layer under melting pack ice. J. Geophys. Res., 88(C5), 2827-2835. 
McPhee, M.G. 1987. A time-dependent model for turbulent transfer in a stratified oceanic boundary layer. $J$. Geophys. Res., 92(C7), 6977-6986.

McPhee, M.G. 1990. Small scale processes. In Smith, W., ed. Polar oceanography. Part A. Physical science. San Diego, CA, Academic Press, 287-334.

McPhee, M.G. and L.H. Kantha. 1989. Generation of internal waves by sea ice. J. Geophys. Res., 94(C3), 3287-3302.

McPhee, M.G., G.A. Maykut and J.H. Morison. 1987. Dynamics and thermodynamics of the ice/upper ocean system in the marginal ice zone of the Greenland Sea. J. Geophys. Res., 92(C7), 7017-7031.

Mellor, G.L. and L. Kantha. 1989. An ice-ocean coupled model. J. Geophys. Res., 94(C8), 10,937-10,954.

Mellor, G.L., M.G. McPhee and M. Steele. 1986. Iceseawater turbulent boundary layer interaction with melting or freezing. J. Phys. Oceanogr., 16(11), $1829-1846$.

Morison, J.H., M.G. McPhee and G.A. Maykut. 1987. Boundary layer, upper ocean, and ice observations in the Greenland Sea marginal ice zone. J. Geophys. Res., 92(C7), 6987-7011.

Svensson, U. and A. Omstedt. 1990. A mathematical model of the ocean boundary layer under drifting melting ice. J. Phys. Oceanogr., 20(2), 161-171.

Yaglom, A.M. and B.A. Kader. 1974. Heat and mass transfer between a rough wall and turbulent fluid flow at high Reynolds and Peclet numbers. J. Fluid Mech., 62, 601-623.

The accuracy of references in the text and in this list is the responsibility of the author, to whom queries should be addressed. 